\section{Fontes científicas em um ecossistema jornalístico: uma nova realidade}

\author{
Victor Israel Gentilli \\ Thalita Mascarelo da Silva
}

\section{Resumo:}

Este estudo reflete sobre as relações sociais e de poder que contextualizam as fontes de informação científicas, compreendidas aqui como promotores de notícias e potenciais influenciadores digitais. A reflexão sobre os modos como essas transformações se configuram no jornalismo é desenvolvida por meio de uma pesquisa teórico-bibliográfica, baseada no questionamento sobre o papel das fontes de notícias nesses processos. Dois percursos teóricos associados sustentam a discussão do trabalho: de um lado, a emergência de um ecossistema jornalístico; de outro, o entendimento da territorialidade e da temporalidade como fenômenos articulados com ênfase nas modificações na circulação da informação jornalística, condicionamentos emergentes das sociedades contemporâneas.

Palavras-chave: Fontes jornalísticas. Promotores de notícias. Ecossistema jornalístico.

\section{Scientific sources in a journalistic ecosystem: a new reality}

\begin{abstract}
:
This study is a reflection on the social and power relations that contextualize the scientific sources of the news, understood here as news promoters and potential digital influencers. The reflection on the ways in which these transformations are configured in journalism is developed based on a theoretical-bibliographic research, based on the questioning of the role of the sources of news in these processes. Two associated theoretical paths support the discussion of the work: on the one hand, the emergency of a journalistic ecosystem; on the other hand, the understanding of territoriality and temporality as articulated phenomena with an emphasis on changes in the circulation of journalistic information, both emerging conditions of contemporary societies.
\end{abstract}

Keywords: : News sources. News promoters. Journalistic ecosystem.
Recebido em: 29.12.20

Aprovado em: 10.08 .21

Victor Israel Gentilli

Professor titular no departamento de Comunicação Social da Universidade Federal do Espírito Santo - Ufes. Docente do corpo permanente do Programa de Pós-graduação em Comunicação e Territorialidades (UFES).

E-mail:vgentilli@gmail. com

\section{Thalita Mascarelo} da Silva

Formada em Comunicação Social/Jornalismo pela Universidade Federal do Espírito Santo. Mestranda do Programa de Pós-Graduação em Comunicação e Territorialidades (UFES).

E-mail: thalitamascarelo@outlook.com 
presente trabalho inscreve-se no panorama das fontes de notícias científicas inseridas no jornalismo em dois territórios distintos: os jornais e as redes sociais. A partir disso, discute as transformações que a interseção desses territórios simbólicos acarreta para a prática do jornalismo. Assim, este artigo explora a possibilidade de articular os conceitos de temporalidade e de territorialidade diante do atual momento transitório e de mudanças tecnocomunicacionais no jornalismo. Essas articulações propostas são alcançadas por meio de uma discussão teórico-reflexiva, a qual abrange compreender o processo informacional das fontes especializadas em ciência de maneira amplificada no jornalismo contemporâneo, compreendendo sua participação como protagonista.

A proatividade das fontes de notícias diante da sua participação em matérias de jornais já foi amplamente discutida, e, inclusive, pesquisadores sugerem diferentes nomenclaturas para se refletir sobre o desempenho das fontes na relação com os jornalistas e jornais. Molotch e Lester (1993), por exemplo, nomeiam-nos news promoters (promotores de notícias), com a intenção de demonstrar o quanto as fontes conseguem disputar protagonismo no campo jornalístico a partir de seu papel como indivíduo que detém informações e conhecimentos de interesse público.

Atualmente, principalmente com as novas plataformas, como Facebook e Twitter, a função de fonte pode ser explorada sem a intermediação dos jornalistas e com ainda mais protagonismo, fazendo com que esses atores se posicionem em uma "zona de penumbra" entre ser um emissor de informação como um jornalista e uma fonte de notícias, o que os torna capazes de serem vistos como influenciadores digitais (MAARES; HANUSCH, 2018). Tal discussão enfraquece a ideia de campo jornalístico, ao mesmo tempo que fortalece a de um ecossistema jornalístico.

O entendimento dessas transformações no modus operandi das fontes as insere no desenvolvimento de um ecossistema jornalístico circunscrito em novas formas de temporalidade nesse ambiente de expansão, ressignificando a institucionalidade das mídias em geral, de modo a multiplicar as práticas midiáticas e, mais especificamente, jornalísticas em novos territórios. A dimensão temporal, desde os primórdios do jornalismo, aparece como um dos demarcadores da especificidade da profissão como fenômeno atuante na construção de um tempo social, experimentada no mundo objetivo do fazer, a partir das relações sociais e das representações de mundo (FRANCISCATO, 2019).

Além da temporalidade, a territorialidade desponta como um conceito de ligação importante para uma compreensão mais ampliada do momento midiático e jornalístico atual, já que é constituída mediante relações e negociações capazes de construir noções de pertencimento-identidade. O momento atual midiático, entendido a partir da territorialidade humana, capacita os indivíduos a habitarem dois mundos: um global, caracterizado pelo processo tecnológico e midiático de acessibilidade ímpar; e outro, local, de acesso delimitado (REIS, 2018). Os atores sociais podem se inserir, concomitantemente, em dois universos díspares, um amplo, outro restrito, sendo a comunicação o processo que une essas transformações de território-territorialidade, a partir do avanço tecnológico de novas mediações dos discursos e das narrativas (REIS, 2018), o que culmina, também, em novas temporalidades, processos de espaço-tempo interligados.

Percebe-se que o meio informacional perpassa processos transformacionais contemporâneos que precisam ser compreendidos, uma vez que estão tendo papel constituidor da realidade atual dos agentes sociais, considerando que a virtualidade está presente na vida social e é capaz de interferir nas tomadas de decisões no cotidiano material (SHIRKY, 2011). No que tange ao jornalismo, diagnósticos recentes demonstram inquietações com o panorama atual, cujas transformações produziram crises construtoras de mudanças estruturais que afetam a infraestrutura e as práticas da profissão. 
Este trabalho explorará a proposição central de estar ocorrendo uma reconfiguração da experiência jornalística diante da experiência informacional em territórios simbólicos que, embora distintos, dialogam e, consequentemente, diante do papel dos atores sociais inseridos no meio jornalístico. $\mathrm{O}$ recorte aqui analisado é o das fontes científicas que, devido ao seu conhecimento específico, atuam dentro do campo jornalístico e possuem, ainda, a capacidade de extrapolá-lo e influenciar diretamente um determinado público se inseridas no âmbito das mídias digitais. Este movimento se faz com os autores conscientes de tratar-se de um olhar direcionado para uma característica específica desse novo ecossistema jornalístico, e não para o seu todo.

\section{A coexistência plural em um ecossistema}

É fato que novas organizações jornalísticas alcançam renome e multiplicam-se nas redes. No Brasil, podemos citar a Agência Pública, o The Intercept Brasil, Os Divergentes, o Jornal Nexo, o Poder 360, a revista Crusoé, entre tantos outros. Como outra característica do mesmo fenômeno, autoridades sociais que possuem cargos reconhecidos na sociedade também podem produzir o próprio espaço informacional e, por si sós, constituem-se em atores cuja informação se torna respeitada, o que transforma seu espaço em território informacional.

A ideia de ecossistema jornalístico permite explicar a diversidade e a integração atual de atores sociais, com base no pressuposto de que as organizações jornalísticas tradicionais já não conseguem cobrir os fatos sociais por si sós (ANDERSON; BELL; SHIRKY, 2013). "Isso coloca instituições estabelecidas na incômoda posição de ter de defender ou até melhorar instâncias do ecossistema atual das quais talvez nem se beneficiem, e que podem beneficiar suas concorrentes" (ANDERSON; BELL; SHIRKY, 2013, p. 79).

Com o relatório de Anderson, Bell e Shirky (2013), que propõe compreender e indicar caminhos para esse momento transitório do jornalismo, surge o termo "ecossistema jornalístico", o qual parte do pressuposto de que há uma interdependência e influência mútua entre os principais atores envolvidos na produção e circulação de informações jornalísticas. "Hoje, é imperativo que a instituição tenha a capacidade de estabelecer parcerias (formais e informais) possibilitadas pelo novo ecossistema" (ANDERSON; BELL; SHIRKY, 2013, p. 76), o que demonstra a importância de se efetuar uma aproximação das redes sociais digitais e das novas mídias. A prática jornalística é marcada por mudanças ao longo de sua história, entretanto a era digital elevou o patamar dessas transformações de modo agudo, fazendo com que os modelos de negócios jornalísticos, as práticas e até as culturas do trabalho se alterassem, tornando as fronteiras do campo jornalístico mais permeáveis (DEUZE; WITSCHGE, 2016).

A base da constituição da prática jornalística está acontecendo de modo computacional, o que modifica a cultura jornalística em sua apuração, em sua rotina, em seus hábitos constituidores de ação, com instrumentos tecnológicos de apoio, como algoritmos, inteligência artificial, automação, redes sociais digitais e big data (FRANCISCATO, 2019), os quais atuam como mediadores tecnológicos tanto para as mídias tradicionais como para outros atores que, com determinada qualificação, conseguem e podem utilizar desses artifícios para concorrer e, ao mesmo tempo, cooperar no espectro informacional, ampliando as experiências socioculturais.

Afetam a lógica de funcionamento das mídias tradicionais, conduzindo-as a operar dentro desse novo espaço informacional; ampliam recursos e competências comunicacionais de produtores e públicos; estabelecem códigos, formatos, possibilidades de conexão, leitura e compartilhamento de unidades textuais diversas; inovam os formatos industriais e alimentam a emergência de novos padrões; intensificam situações de trânsito entre for- 
mas de mediação midiática, particularmente a institucional (geradas no seio das mídias) e a interacional (desencadeadas nos encontros pulverizados pelas redes sociais digitais) (FRANCISCATO, 2019, p. 9).

Neste artigo, portanto, ao se falar em "ecossistema jornalístico", está se ampliando a compreensão do processo informacional, que não somente parte das instituições jornalísticas, isto é, de redações e jornalistas profissionais, mas também inclui outras ações informacionais a partir das novas mídias. Trata-se de um panorama de mudança permanente que impõe às organizações jornalísticas adaptação (ANDERSON; BELL; SHIRKY, 2013), pois a circulação e a distribuição da informação estão acontecendo em diferentes territórios.

Compreende-se a importância do conceito de Bourdieu sobre campo para se delimitar o espaço construído e ocupado historicamente de modo legítimo pelo jornalismo, no entanto a atividade jornalística atualmente não acontece de modo linear a partir de atores pré-estabelecidos e imutáveis (repórteres e editores) e de sua relação com as fontes de notícias. Neste século, em contrapartida, prevalece um "choque de inclusão que se dá de fora para dentro" (ANDERSON; BELL; SHIRKY, 2013, p. 72), e entende-se tal inclusão não como promovida pelos atores tradicionais do campo, mas vinda de fora do campo jornalístico. Por isso, ecossistema jornalístico aparece como um novo conceito importante a ser adotado, pelo menos por enquanto, neste momento de transformação e transição do jornalismo.

\footnotetext{
[...] Não estamos sugerindo que os campos sociais se diluirão em favor de uma espécie de "comunicação direta" da sociedade através de redes difusas. Mas afirmamos que as mudanças decorrentes de processos de interação "em midiatização" modificam (e modificarão crescentemente) o perfil, os sentidos e os modos de ação dos campos sociais; que outros campos se desenvolvem; e sobretudo que os modos de interação entre os campos sociais e entre cada um destes e a sociedade ao largo continuarão a se modificar (BRAGA, 2012, p. 46).
}

Ecossistema jornalístico será um conceito importante, portanto, para o entendimento da ascensão de um determinado agente no jornalismo: os especialistas em ciências. Estes fazem parte de um público muito particular do jornalismo, pois atuam como fontes de notícias que fornecem seus conhecimentos como especialistas em determinada área, ao mesmo tempo que, nos canais próprios de comunicação, são fontes de informação, misturando-se aos mais diversos públicos que atuam no ecossistema jornalístico. Dessa forma, quer-se compreender a transformação desses atores científicos específicos no jornalismo de modo articulado e coexistente no campo e no ecossistema, uma vez que, aqui, entende-se a diferenciação de tais conceitos, os quais não são excludentes, e sim cada vez mais inter-relacionados.

De acordo com Recuero (2009), as redes podem ser relacionadas com a produção jornalística no papel de fontes produtoras de informação, como os cientistas, já que detêm informações de cunho científico que gozam de credibilidade. Assim, o objeto em questão ocupa dois campos: o campo científico e o campo jornalístico - no primeiro, é um agente ortodoxo, que imprime sua fala e legitimidade ao campo em seu papel de especialista; no segundo, ocupa um papel ora ortodoxo, ora heterodoxo. Ao atuar no papel de fonte de notícias, precisa compreender as especificidades, as regras e as lógicas do campo para interagir com os seus atores.

Esse agente social, ainda e muitas vezes, insere-se, por meio do próprio canal de comunicação, nas redes sociais, fazendo parte do denominado ecossistema jornalístico como um especialista que dialoga com o campo jornalístico de maneira distinta (de fora para dentro), a partir do que é publicado. Sendo assim, o especialista, que possui o próprio campo específico, atualmente pode atuar de duas formas no processo informacional como fonte de informação: no território dos 
jornais (campo jornalístico) e no território das redes (ecossistema jornalístico), podendo ser compreendido como um potencial promotor de notícias.

A expressão fontes de notícias estabelece uma situação em que o jornalista "vai até a fonte", sugerindo uma atribuição ativa ao jornalista, o que atualmente não acontece como regra geral, tendo em vista que as fontes estão trabalhando de forma substancialmente atuante, muitas vezes procurando os jornalistas (ALMEIDA, 2010). Em uma formulação mais rebuscada, os sociólogos Harvey Molotch e Marylin Lester (1993) avançaram o conceito de fontes de notícias para o de "promotores das notícias" (news promoters), o qual define as fontes que, condicionando uma agenda própria, transformam fatos, ideias ou projetos em acontecimentos suscetíveis de serem imediatamente noticiados. A influência de determinadas fontes nos jornais atravessaria três níveis, os quais as colocam em uma relação de força com os jornalistas: primeiramente, há as fontes emissoras, que objetivam divulgar determinados acontecimentos para um público geral; no segundo nível, estão os jornalistas que divulgam em notícias esses materiais, recebidos e enviados pelos promotores; e, no último nível, estão os cidadãos que obtêm a informação dos fatos mediante os meios de comunicação (MOLOTCH; LESTER, 1993).

A prática profissional entre jornalistas e fontes ocorre por meio de negociações, e, ao longo destas, os promotores de notícia participantes são decisivos no processo jornalístico, convertendo-se também em produtores de conteúdos, o que assegura seu espaço e poder de interferir no meio noticioso (SCHMITZ, 2011). Atualmente esse conceito de Molotch e Lester pode ser revisitado e atualizado, de forma que agregue também o papel desses promotores de notícias nas redes sociais, em um ecossistema jornalístico, uma vez que essas fontes emissoras estão atuando em um contexto mais ampliado. Não há como analisar o jornalismo contemporâneo e refletir sobre ele somente discutindo o que acontece no jornalismo feito em redações. Nessa atual e complexa conjuntura que agrega o trabalho jornalístico junto às mídias sociais, afetando e modificando diretamente a prática do jornalismo, é preciso compreender o que os atores informacionais criam e fazem circular por lá.

Dessa forma, quem são os news promoters que podem ser considerados parte do ecossistema jornalístico? Primeiro, precisa-se compreender que essas fontes articuladoras nas redes sociais, devido ao cunho informacional em ciência, podem gerar um grande interesse público, de maneira que podem ser também potenciais digital influencers.

Muito do momento atual caracteriza-se por crises institucionais, fake news e pós-verdade, bem como pelo descrédito ao científico e às instituições que trabalham com a verdade factual, como se opinião pudesse se equiparar - e se sobrepor - à "verdade fatual [...] tão obviamente ao alcance de todos" (ARENDT, 1988, p. 294), ao conhecimento, à legitimidade de algo cientificamente estudado e provado. Os news promoters, portanto, trabalham de forma paralela a essa realidade desfigurada, podendo fazer parte de um espectro social o qual tenta, por meio de argumentos factíveis e científicos, enfrentar as fake news em disputas de narrativas.

O momento atual proporciona uma mudança no papel social das fontes de notícias a partir das redes sociais que influenciam a prática jornalística, na medida em que muito do que se comunica nas redes também é informação qualificada. Isso impele adaptações às organizações jornalísticas, que passam a incluir as redes sociais como um novo meio de acesso às fontes, devido à facilidade, intensificada nessas redes on-line, de encontrar especialistas que auxiliem na construção de pautas e em informações em primeira mão (RECUERO, 2009).

As redes sociais são um novo espaço público ao qual os indivíduos estão aderindo com o intuito de se comunicarem e de se informarem. Tomadas em seu papel informativo, podem ser um espaço de reverberação informacional complementar à função jornalística, embora não tenham o mesmo comprometimento 
com a credibilidade da informação que os jornais têm (RECUERO, 2009). Vale enfatizar que, à primeira vista, profissionais da saúde que possuem redes sociais com o intuito de informar sobre seu trabalho podem ser considerados credíveis e comprometidos com a informação adicionada em suas postagens públicas. Ainda que se possa questionar a responsabilidade social na divulgação de informações sobre saúde em uma rede social, a função social do jornalismo também pode ser questionada e reavaliada em um momento de crise e de tantas mudanças. Em um primeiro olhar, portanto, a informação postada por um nutricionista, por exemplo, em suas redes sociais pode ser compreendida como de relevância e credibilidade, assim como o é em um jornal, podendo atuar de forma próxima e complementar à jornalística.

Nessas novas ferramentas, esses especialistas também podem ser categorizados como celebridades, visto que obtêm visibilidade e notoriedade, como Dráuzio Varella faz, transitando entre meios de comunicação tradicionais e as novas mídias digitais, e assim como Átila Iamarino se tornou referência científica, tendo surgido como divulgador científico no YouTube. Esse ecossistema gera protagonismos individuais, um ambiente de celebridades, influenciadores digitais e uma exacerbada fragmentação de informações em conjunto com desinformação e entretenimento, amplificada pela ação de algoritmos. O jornalismo enfrenta uma disputa de atenção inédita, que gera, consequentemente, desconfiança entre o público e as grandes instituições que optam, muitas vezes, por creditar confiança nos indivíduos e na pessoalidade gerada (CHRISTOFOLETTI, 2019).

\section{A territorialidade e a temporalidade na tríade circulação-poder-comunicação}

Esse recente histórico de descentralização da circulação da informação e da multiplicidade de informações no âmbito social afeta as características fundamentais da profissão, principalmente a lógica de fechamento nas redações, que atualmente precisa operar em um fluxo contínuo, "minuto a minuto", de modo onipresente, o que acarreta mudanças na temporalidade do trabalho e, concomitantemente, no trabalho de produção-apuração cotidiana. Vale observar não se tratar de mudança pequena. A marca da periodicidade (diária, semanal, mensal etc.) que implica um momento de fechamento, de conclusão e feitura de um todo, hierarquizado e organizado, foi definidora do jornalismo que se consagrou no século XX. E esta nova realidade quebra essa lógica, em boa medida rompe com sua característica mais forte, que marcou e definiu os jornais ao longo da história, a periodicidade. Também a totalidade se flexibiliza com a lógica do fluxo contínuo, em especial quando associada à quebra da hierarquização definida pela lógica contábil das views. O que conhecemos como "edição", seja como resultado final do ato de editar, seja como um todo finalizado, perde praticamente todo o seu sentido original.

São novos territórios sendo ocupados e territorializados por agentes sociais 24 horas por dia, todos os dias da semana. Isso gera e altera o entrelaçamento de territórios simbólicos virtuais e novas temporalidades de modo distinto do que acontece no mundo material. A mídia digital derrubou a temporalidade do consumo de notícias, gerando ainda mais questões para os denominados furos de reportagem, acelerando ritmos e conduzindo ainda mais riscos para as reportagens de qualidade. A inserção de novos e muitos atores no relacionamento com essas informações nas redes sociais altera as narrativas a cada compartilhamento, a partir de interpretações e condicionamentos diversos.

Olhando para a circulação digital, a autoridade epistêmica do jornalismo deve ser entendida como uma luta árdua em vez de assumida. Mesmo que as notícias sejam produzidas de acordo com as práticas tradicionais, elas são transmitidas e transformadas por uma variedade de agentes. As notícias circulam junto com comentários e desafios, são reembala- 
das por novos agregadores e ganham "curtidas" e "retuítes" nas redes sociais (CARLSON, 2020, p. 243, tradução livre nossa).

Essas transformações que culminam em novas mediações têm como bojo a tecnologia, que, ao ser utilizada, modifica as temporalidades e as territorialidades no jornalismo. Barbero (2018) denomina "tecnicidade" o elemento sociocultural que conecta as redes no meio on-line, assim como em outros meios, como a televisão ao computador. As fontes de notícias utilizam dessa tecnicidade para se promoverem tanto no território dos jornais, com seus qualificados releases por intermédio do computador, quanto no território das redes, nos próprios canais de comunicação, criando territorialidades a partir das relações sociais e de poder estabelecidas, tendo o potencial de influenciadores digitais.

Território pode ser compreendido, sob a perspectiva de Saquet (2015), como um condicionante das temporalidades e das territorialidades que se concretizam entre os atores sociais nas relações espaço-tempo significando interação plural. $\mathrm{O}$ território é um espaço que foi ocupado, criado, por meio da vida social e das relações de poder significadas a partir da comunicação. Diante disso, a comunicação aparece como polo central de ligação-interação em um território, sendo característica fundamental das territorialidades (RAFFESTIN, 1993).

As temporalidades são os ritmos existentes nos territórios que coexistem de maneiras distintas, alguns mais lentos, outros mais rápidos. Atualmente, prevalecem os ritmos das simultaneidades, das redes, das múltiplas relações e identidades, logo as distâncias espaciais se modificam, comprimem-se, articulam-se temporalidades e territorialidades (SAQUET, 2015). Na contemporaneidade, o processo jornalístico busca atingir um ritmo acelerado que o mantenha competitivo e perceptível em um mundo em que os territórios simbólicos estão cada vez mais acessíveis aos públicos. De acordo com a pesquisa TIC Domicílios, divulgada pelo portal G1 em 28 de agosto de 2019, realizada anualmente pelo Centro Regional de Estudos para o Desenvolvimento da Sociedade da Informação (Cetic), houve um crescimento no acesso à internet no país em 2018: de 67\% para 70\% dos brasileiros usaram regularmente a internet no ano de 2018, o que equivale a 126, 9 milhões de pessoas, com aumento entre as classes D e E e nas regiões rurais (LAVADO, 2019).

A crescente popularização da internet faz com que as redes sociais demarquem um novo momento de interação sociocultural desafiador para diversos âmbitos de estudos, como a tentativa de compreender como a saúde mental dos indivíduos é afetada, como fazer valerem os direitos humanos na virtualidade, como as pessoas estão se relacionando com a circulação de informações e qual é, de fato, o papel desses gigantes globais nas consequências sociais de suas plataformas. O Facebook, por exemplo, foi criado em 2004 e o Twitter, em 2006, duas redes sociais de acesso global intenso, inclusive por parte de jornais, jornalistas, cientistas, profissionais da saúde e público em geral a partir da criação de perfis. Dados de abril de 2020 apontam o Facebook como a mais popular rede social, com cerca de 2,5 bilhões de usuários; já o Twitter conta com 386 milhões de usuários ativos, sendo no Brasil 14,5 milhões de usuários (STATISTA, 2021) ${ }^{1}$. A pandemia e o isolamento social fizeram com que houvesse, ainda, um crescimento do uso das redes sociais, evidenciado pelo relatório feito pelo Twitter em 2020 indicando um aumento anual de $24 \%$ de usuários ativos, o maior número registrado em um ano (TWITTER, 2020).

O território, principalmente virtual e das redes, está em constante transformação, devido ao contexto descontínuo capitalista em que está inserido e, por isso, desterritorializa-se e reterritorializa-se de acordo com as relações estabelecidas entre os seres humanos e o ambiente, a partir das temporalidades (ritmos) e das territorialidades (relações sociais e de poder) existentes (SAQUET, 2015). Isso acontece devido ao interesse do capital em acessar os mundos construídos e poder controlá-los.
${ }^{1}$ Os dados apresentados foram consultados no portal Statista em 12 de dezembro de 2020. Porém, a publicação consultada passou por atualizações, de modo que o link referenciado direciona para um levantamento de dados referentes apenas a 2021. Por esse motivo, há referência a Statista (2021). 
"Se não na sua materialidade, pelo menos na hegemonia da sua lógica, este sistema socioeconômico finca raízes nos mais recônditos lugares, mesmo na forma da sua negatividade, onde se consolida a pobreza material" (REIS, 2018, p. 24).

É importante frisar a relação que há entre capital e circulação e como essa questão implica diretamente a tentativa de apropriação e exploração do jornalismo pelo capital. A circulação de bens e serviços (material) e da comunicação (cultural) a partir de redes é fundamental na busca pela ampliação da dominação do capital nos territórios, sendo estratégico o seu modo destruidor-criador que facilita o rompimento de barreiras em uma lógica global (SAQUET, 2015).

A questão-chave diz respeito à tríade: circulação-comunicação-poder. Raffestin (1993) dedica-se a entender territorialidade a partir da concepção de poder foucaultiana: poder como algo relacional e presente em toda relação humana de modo multidimensional, vinculando-se ao espaço-tempo. O jornalismo e suas narrativas, portanto, são capturados nas redes de circulação, como um serviço a ser controlado, embora, partindo da linha foucaultiana, o jornalismo possa enfrentar esse domínio na relação estabelecida com o capital. O estabelecimento de um confronto relacional de poder poderia acontecer com base em princípios éticos jornalísticos que priorizassem o interesse público e a qualidade da informação em detrimento do lucro, uma vez que o embate e a negociação fazem parte de toda e qualquer relação de poder.

O momento vigente, todavia, é provocador, não dependendo apenas do domínio do jornalista ou dos jornais para se estabelecer como ético e de qualidade. A circulação da informação jornalística nas mídias diversas não é uma extensão da produção de notícias como conhecimento, mas uma parte central do exame jornalístico como sistema epistêmico (CARLSON, 2020), tendo em vista que recai na imagem e no questionamento da autoridade do jornalismo em si. Isto é, nas redes sociais, as informações se tornam difusas, fragmentadas, complementadas por diferentes atores, podendo tornar o entendimento da informação multifacetário.

As relações de poder, portanto, são fundamentais para se compreender esse processo, pois fazem parte de uma contextualização da função das fontes de notícias no campo e no ecossistema jornalístico. Este artigo apropria-se, pois, da ideia de poder proposta por Michel Foucault (1976), o qual afirma que o poder não reside em lugar algum, o poder se exerce relacionalmente entre os sujeitos. Assim, de modo distinto do modo tradicional de se entender poder, a perspectiva foucaultiana trabalha com a ideia de que o poder é difuso e, por isso, não é localizável (HENRIQUES, 2010).

Cabe, assim, a associação dessas relações de poder a partir dos conflitos e ordenamentos existentes no campo e no ecossistema jornalístico do qual as fontes especialistas fazem parte ao se disporem a informar em uma determinada esfera pública. Com efeito, a disputa parte de um capital simbólico, o qual cada um dos atores procura legitimar e consolidar. Atualmente, o fator preponderante para se pensar territorialidade e temporalidade dentro do campo comunicacional diz respeito ao processo de midiatização tecnossocial, o qual impulsiona a interseção entre territórios simbólicos constituídos, territorialidades, temporalidades e comunicação.

Destarte, as fontes de notícias especializadas que ocupam um espaço simbólico nas redes, ao se apropriarem desse espaço e interagirem e informarem, transformam tal espaço de virtualidade em território efetivado por territorialidades (com relações sociais e de poder específicas, por meio de narrativas e discursos). Territorialidades constituídas em um território simbólico nada mais são que a semantização, a significação, a territorialização daquele espaço, aspectos construídos pelos atores ali presentes mediante a comunicação.

Nas redes sociais, essas relações de poder são entendidas como algo diluído na virtualidade, a partir da liberdade de uma rede produtiva que atravessa todo o corpo social, produzindo narrativas, discursos e informações - embora a relação 
de poder do especialista com essa nova realidade comunicativa tecnológica em um ecossistema jornalístico o coloque como protagonista de seu espaço, não significa que ele tenha o controle total do que acontece naquele território virtual, uma vez que a interação nas redes sociais constitui-se em relações de poder que podem relativizar a hierarquização entre quem emite a informação e quem a recebe, atores muito mais ativos. Ademais, devido ao número exorbitante de atores nessas redes on-line, seu espaço ocupado é demasiadamente fluido: aparece, desaparece e reaparece nas bolhas comunicacionais formadas pelos usuários e algoritmos.

Nos jornais, a territorialidade construída é outra, visto que a relação das fontes nesse meio muda, por intermédio dos agentes daquele campo. "Consideramos territórios como acontecimentos que resistem por um tempo, aderindo a substratos espaciais que podem ser tangíveis ou não, enquanto que territorialidades se referem aos processos, ordens e valores que os sustentam" (REIS, 2018, p. 24). Pensando no campo jornalístico, as relações de poder acontecem de maneira consideravelmente rígida, hierárquica e com constante disputa de fala. As fontes especialistas participam dessas relações de poder, como já dito, por meio daquilo com que podem contribuir cientificamente, o que faz com que seu capital simbólico atinja característica persuasiva no campo jornalístico; porém, isso não significa que sua fala será imposta dentro desse campo exatamente como a fonte almeja e deseja, de forma que acontece uma disputa constante nas relações sociais existentes no contexto do trabalho jornalístico. O número de participantes das relações constituídas nos jornais, no campo, é muito reduzido, quando comparado ao que se vê no grande ecossistema jornalístico, além de o lugar de emissores e receptores ser muito mais pré-estabelecido.

Quando o campo se relaciona com o ecossistema, realidades distintas fundem-se gerando um emaranhado de novas formas informacionais. Assim como muitas fontes científicas utilizam de redes sociais para informarem e estabelecerem vínculos entre si e com o público em geral, jornalistas também o fazem, o que gera um aumento rápido e contínuo de relacionamentos entre jornalistas e novas fontes nesse novo espaço, que, com o intermédio do jornalista, pode também extrapolar as mídias sociais. Natália Pasternak, pesquisadora e microbiologista, surge como um novo exemplo que vem se destacando nesse sentido, ao utilizar o Twitter diariamente com o intuito de divulgação científica e participar ativamente da denominada mídia tradicional. Por meio de contatos com diferentes jornalistas, ela é chamada para entrevistas em jornais, telejornais, lives, podcasts etc., inclusive também atua como colunista no jornal O Globo. É um circuito midiático proporcionado também devido às redes sociais, embora não se limite a elas.

Entende-se, então, que o ciberespaço, a compressão espaço-tempo e a globalização geram crises de fronteiras que dão indícios de desterritorialização. Tal processo deve ser entendido de maneira associada ao da multiterritorialidade, com a reterritorialização praticada pelos sujeitos que se apropriam de novos espaços na internet. Um site consiste em uma territorialização ou uma des-re-territorialização, uma vez que ali relações de controle e de fuga podem ser exercidas, destruindo hierarquias, ao mesmo tempo que pode instituir hierarquias, em um processo complexo de des-re-territorializações (LEMOS, 2011).

Dialogando com Lemos, Haesbaert (2004), autor da geografia que se empenha em compreender os conceitos de território (termo polissêmico), afirma que os territórios não estão se dissipando, mas se deslocando constantemente, processo que resulta em uma multiplicação de territórios, o que altera o sentido relacional, suas significações e territorialidades, desenvolvendo um processo complexo e convergente à ideia de rede. Ademais, Haesbaert, já em 1994, em seu texto intitulado $O$ mito da desterritorialização e as 'regiões rede', dizia que o deslocamento entre territórios não significava abrir mão das referências territoriais já estabelecidas, mas formar outras. Os especialistas, por sua vez, não deixam de estar como fontes 
de notícias em jornais pelo fato de se apropriarem de um território virtual e se tornarem fontes de informação por lá, apenas adiciona-se mais um lugar para se relacionarem e se fazerem ser vistos.

Outra questão significativa levantada por Raffestin (1993) diz respeito ao que o geógrafo francês entende como uma relação inversa entre o alcance temporal e o alcance espacial. "O planeta pode ser reorganizado de tal maneira que nenhum ponto fique isolado e, dessa forma, o espaço é perfeitamente dominado. Mas o que acontece com o tempo?" (RAFFESTIN, 1993, p. 212). Para ele, a circulação de energia sustenta a informatização, de forma que, atualmente, muito do espaço não está mais isolado; porém, o tempo trabalha de outra forma, no sentido de que a informação se perde (RAFFESTIN, 1993). O controle do tempo não acontece como o da expansão espacial feita pelo homem a partir da globalização, que Saquet (2015) entende como um fluxo incessante do capital de desterritorialização, multerritorialização, reterritorialização.

Raffestin (1993) acredita ser o domínio do tempo praticamente impraticável, de curta duração, fraco, sugerindo um mundo dominado por uma concepção de poder que se fixa mais no espaço que no tempo. Essa reflexão, apesar de concluída no final do século passado, contribui com a questão atual da ideia de espaço-tempo, uma vez que os espaços são de fato perpassados pelas redes de circulação, materializadas pelos meios de transporte, de controle do capital cada vez mais de modo global. Em contrapartida, as redes comunicacionais estão criando dimensões demasiadas, o que torna complexo o controle dessa hiper(des)informação, o que Silverstone entende como descontroles, vulnerabilidades do capital que geram "um mundo cada vez mais nervoso" (SILVERSTONE, 2002, p. 201), onde muito se esquece rapidamente, colocando em perigo o lugar da memória na contemporaneidade.

Observa-se que territorialidade extrapola a ideia de relações de poder político, envolvendo também aspectos econômicos e ambientais no espaço-tempo, significando cotidianidades, pluralidades, pertencimento no território (SAQUET, 2015). Com base nisso e com a utilização da tecnologia, um novo meio é capaz de uma possível reestruturação do poder (RAFFESTIN, 1993). As invenções ao longo da história demonstram isso, com a influência que um dia o telégrafo causou nas relações sociais, assim como a internet e sua utilização pelos sujeitos ganham significação cultural e rearranjam estruturas relacionais sociais e de poder criando novos territórios.

As redes sociais, portanto, fazem parte do processo histórico-tecnológico de influência na vida social e, no que diz respeito ao jornalismo digital, atuam de maneira complementar e colaborativa (RECUERO, 2009). "Podem ser constituídas, por exemplo, de um perfil no Instagram, no Facebook, no Twitter, um canal no YouTube, um blog, etc. Redes sociais na Internet podem ser muito maiores e mais amplas que as redes off-line, com um potencial de informação que está presente nas conexões" (RECUERO, 2009, p. 2).

As informações nos auxiliam a nos inserirmos num contexto histórico, econômico, político e cultural. A crise do jornalismo consiste em um fenômeno complexo e dinâmico, de difícil enfrentamento e sem solução única e rápida. É preciso adaptar-se às tecnologias, às novas plataformas digitais, sem se limitar a elas.

\section{Considerações finais}

Em uma lógica interacional, as novas mídias sociais constituem novos espaços comunicacionais que tornam os processos informacionais mais complexos, amplos e multidimensionais. Este novo cenário implica inúmeras novas questões e repta profissionais da ciência, jornalistas e pesquisadores. Uma destas questões, talvez a central, é: se o papel de mediação na circulação de informações de interesse público já não é exclusivo dos jornais, qual é o papel diferencial e legitimador do campo jornalístico atualmente? 
É preciso um engajamento político-social em busca do fortalecimento do campo jornalístico baseado no protagonismo dos jornais e dos jornalistas: sua função social, o interesse público e o papel de mediar informações de modo perito com interpretação, com humanização de dados, com criticidade, com apuração e investigação.

Ressalta-se o interessante papel de especialistas, no caso aqui, do campo científico a partir do próprio espaço informacional, uma vez que possuem conhecimentos específicos de interesse à população. $\mathrm{O}$ atual cenário evidencia, grosso modo, duas diferentes maneiras de se praticar o ato informacional. A primeira é embasada na apuração e na investigação; a segunda se constitui, majoritariamente, de conhecimentos específicos adquiridos na prática e no domínio técnico desses profissionais. São atuações informacionais que partem de procedimentos, experiências, narrativas, ethos e lugares distintos disputando a atenção das pessoas.

Este texto é um primeiro esboço de discussão de um tema tão novo quanto relevante, de enorme atualidade, que se apresenta como um desafio aos pesquisadores de jornalismo e a todos os demais envolvidos nesta nova realidade, pois, embora haja empenho de pesquisadores no entendimento atual do cenário que está sendo apresentado, ainda existem dúvidas em relação à reorganização do espaço de atuação jornalística. Os próprios atores sociais - jornalistas, fontes, empresários, públicos, anunciantes etc. - parecem estar ainda em um processo de negociações e concordâncias sobre como reconfigurar a prática jornalística nos próximos anos, neste novo cenário de inovações (ADGHIRNI; PEREIRA, 2011). Assim, para se compreender melhor e de forma empírica o atual momento de convergência entre esses dois territórios simbólicos, suas diferenciações e semelhanças, é preciso um aprofundamento sobre como essas práticas informacionais e as intenções por parte dos atores da informação são formadas sob a ótica jornalística em um momento de tensões e transformações tecnológicas e econômicas no campo.

\section{Referências}

ADGHIRNI, Z. L.; PEREIRA, F. H. O jornalismo em tempos de mudanças estruturais. Intexto, Porto Alegre, v. 1, n. 24, p. 38-57, jan./jun. 2011.

ALMEIDA; B. C. A. M. Casamento de conveniência: a relação entre fontes e jornalistas. Comunicação \& Informação, Goiânia, v. 13, n. 2, p. 30-40, jul./dez. 2010.

ANDERSON, C. W; BELL, E; SHIRKY, C. Jornalismo pós-industrial: adaptação aos novos tempos. Revista de Jornalismo ESPM, São Paulo, n. 5, ano 2, p. 30-89, abr./jun. 2013.

ARENDT, H. Entre o passado e o futuro. São Paulo: Editora Perspectiva, 1988.

BARBERO, J. M. Dos meios às mediações: 3 introduções. MATRIZes, São Paulo, v. 12, n. 1, p. 9-31, jan./abr. 2018.

BRAGA, J. L. Circuitos versus Campos Sociais. In: MATTOS, Maria Ângela; JANOTTI JÚNIOR, Jeder; JACKS, Nilda (org.). Mediação e Midiatização. Salvador: EDUFBA, 2012. p. 31-52.

CARLSON, M. Journalistic epistemology and digital news circulation: Infrastructure, circulation practices, and epistemic contests. New media \& society, [s. l.], v. 22, n. 2, p. 230-246, 2020. 
CHRISTOFOLETTI, R. A crise do jornalismo tem solução? Barueri: Estação das Letras e Cores, 2019.

DEUZE, M.; WITSCHGE, T. O que o jornalismo está se tornando. Parágrafo, São Paulo, v. 4, n. 2, jul./dez. 2016.

FOUCAULT, M. História da Sexualidade I: A Vontade de Saber. Lisboa: Relógio d'água, 1976.

FRANCISCATO, C. E. Tecnologias digitais e temporalidades múltiplas no ecossistema jornalístico. Contracampo, Niterói, v. 38, n. 2, p. 132-146, ago./nov. 2019.

HAESBAERT, R. O mito da desterritorialização e as "regiões-rede". In: CONGRESSO BRASILEIRO DE GEÓGRAFOS, 5, Curitiba, 1994. Anais... Curitiba: Associação de Geógrafos Brasileiros, 1994. p. 206-214.

HAESBAERT, R. O mito da desterritorialização: do "fim dos territórios" à multiterritorialidade. Rio de Janeiro: Bertrand Brasil, 2004.

HENRIQUES, R. P. Poder e resistência: o estado e as rádios pirata. Rádio-leituras, Ouro Preto, v. 1, n. 1, p. 83-104, jul./dez. 2010.

LAVADO, T. Uso da internet no Brasil cresce, e $70 \%$ da população está conectada. G1, Seção Economia, subseção Tecnologia, [s. l.], 28 ago. 2019. Disponível em: $<$ https://g1.globo.com/economia/tecnologia/noticia/2019/08/28/uso-da-internetno-brasil-cresce-e-70percent-da-populacao-esta-conectada.ghtml >. Acesso em: 20 dez. 2019.

LEMOS, A. Cultura da mobilidade. In: FERLA, Jorge; BEIGUELMAN, Giselle. Nomadismos tecnológicos. São Paulo: Ed. Senac São Paulo, 2011. p. 1-12.

MAARES, P.; HANUSCH, F. Exploring the boundaries of journalism: Instagram micro-bloggers in the twilight zone of lifestyle journalism. Journalism, [s. l.], v. 21, n. 2, p. 262-278, 2018.

MOLOTCH, H; LESTER, M. As notícias como procedimento intencional: acerca do uso estratégico de acontecimentos de rotina, acidentes e escândalos. In: TRAQUINA, Nelson (org.). Jornalismo: questões, teorias e estórias. Lisboa: Vega, 1993, p. 34-51.

RAFFESTIN, C. Por uma geografia do poder. São Paulo: Ática, 1993.

RECUERO, R. Redes Sociais na Internet, Difusão de Informação e Jornalismo: Elementos para discussão. In: SOSTER, D. de A.; FIRMINO, F. (org.). Metamorfoses jornalísticas 2: a reconfiguração da forma. Santa Cruz do Sul: UNISC, 2009. p. 1-269.

REIS, R. Propostas para um programa de estudos sobre Comunicação e territorialidades. In: ZANETTI, D.; REIS, R. (org.). Comunicação e territorialidades: poder e cultura, redes e mídias. Vitória: EDUFES, 2018, p. 22-34. 
SAQUET, M. A. Por uma geografia das territorialidades e das temporalidades: uma concepção multidimensional voltada para a cooperação e para o desenvolvimento territorial. 2. ed. Rio de Janeiro: Consequência, 2015.

SCHMITZ, A. A. Fontes de notícias: ações e estratégias das fontes no jornalismo. Florianópolis: Combook, 2011.

SHIRKY, C. The political power of social media: Technology, the public sphere, and political change. Foreign affairs, Nova Iorque, v. 90, n. 1, p. 28-41, 2011.

SILVERSTONE, R. Por que estudar a mídia? São Paulo: Loyola, 2002.

STATISTA. Twitter - Statistics \& Facts. Industry Internet, topic Social Media \& User-Generated Content, [s. l.], 4 mar. 2021. Disponível em: <https://www.statista.com/topics/737/twitter/>. Acesso em: 12 dez. 2020.

TWITTER. Q1' 2020 Shareholder Letter. [s. l.], 2020. Disponível em: <https:// investor.twitterinc.com/home/default.aspx>. Acesso em: 12 dez. 2020. 